Fetal Diagnosis and Therapy

\title{
Definition of Failed Induction of Labor and Its Predictive Factors: Two Unsolved Issues of an Everyday Clinical Situation
}

\author{
Núria Baños Federico Migliorelli Eduardo Posadas Janisse Ferreri \\ Montse Palacio \\ BCNatal - Barcelona Center for Maternal-Fetal and Neonatal Medicine, Hospital Clínic and Hospital Sant Joan \\ de Deu, Fetal i+D Fetal Medicine Research Center, IDIBAPS, University of Barcelona, Barcelona, Spain
}

\section{Key Words \\ Induction of labor · Failed induction of labor · Predictive factors · Transvaginal ultrasound}

\begin{abstract}
Objective: The objectives of this review were to identify the predictive factors of induction of labor (IOL) failure or success as well as to highlight the current heterogeneity regarding the definition and diagnosis of failed IOL. Materials and Methods: Only studies in which the main or secondary outcome was failed IOL, defined as not entering the active phase of labor after $24 \mathrm{~h}$ of prostaglandin administration $\pm 12 \mathrm{~h}$ of oxytocin infusion, were included in the review. The data collected were: study design, definition of failed IOL, induction method, IOL indications, failed IOL rate, cesarean section because of failed IOL and predictors of failed IOL. Results: The database search detected 507 publications. The main reason for exclusion was that the primary or secondary outcomes were not the predetermined definition of failed IOL (not achieving active phase of labor). Finally, 7 studies were eligible. The main predictive factors identified in the review were cervical status, evaluated by the Bishop score or cervical length. Discussion: Failed IOL should be defined as the inability to achieve the active phase of labor, considering
\end{abstract}

that the definition of $\mathrm{IOL}$ is to enter the active phase of labor. A universal definition of failed $I O L$ is an essential requisite to analyze and obtain solid results and conclusions on this issue. An important finding of this review is that only 7 of all the studies reviewed assessed achieving the active phase of labor as a primary or secondary IOL outcome. Another conclusion is that cervical status remains the most important predictor of IOL outcome, although the value of the parameters explored up to now is limited. To find or develop predictive tools to identify those women exposed to IOL who may not reach the active phase of labor is crucial to minimize the risks and costs associated with $\mathrm{OOL}$ failure while opening a great opportunity for investigation. Therefore, other predictive tools should be studied in order to improve IOL outcome in terms of health and economic burden.

(c) 2015 S. Karger AG, Basel

\section{Introduction}

The induction of labor (IOL) has become more frequent in recent years, occurring in about $20 \%$ of almost all settings $[1,2]$. Concerns about IOL indications, management and outcomes are rising in proportion to this rate. The IOL is defined as the artificial initiation of labor

\section{KARGER 125}

(c) 2015 S. Karger AG, Base

$1015-3837 / 15 / 0383-0161 \$ 39.50 / 0$

E-Mail karger@karger.com

www.karger.com/fdt
Núria Baños, MD, BCNatal - Barcelona Center for Maternal-Fetal and Neonatal Medicine, Hospital Clínic and Hospital Sant Joan de Déu Fetal i+D Fetal Medicine Research Center, IDIBAPS

University of Barcelona, Sabino de Arana 1, ES-08028 Barcelona (Spain) E-Mail NBANOS@clinic.ub.es 
[3]. On the other hand, cervical ripening is defined as a prelude to the onset of labor, whereby the cervix becomes soft and compliant, either occurring naturally or as a result of physical or pharmacological interventions [3]. Cervical ripening by physical or pharmacological methods and labor induction should not be confused, even though the literature usually refers to labor induction as the process also including cervical ripening. Although the definition of labor induction is simple, criteria for successful and failed IOL have not been standardized and no consensus has been reached to date. Regarding IOL outcome, a variety of endpoints such as mode of delivery (vaginal delivery or cesarean section), vaginal delivery within a certain time interval or achievement of the active phase of labor have been suggested. As a consequence, comparison between published studies becomes a complicated issue due to the existing heterogeneity in the literature.

\section{Definition of IOL, Failed IOL and Cesarean Section for Failed IOL}

Some authors have expressed their concerns about IOL and the definition of failed IOL $[1,2]$. Lin and Rouse [2] suggested a practical definition of failed IOL, which should maximize the number of women progressing to the active phase of labor while maintaining a low incidence of adverse maternal and neonatal outcomes. They define failed IOL as the inability to achieve cervical dilatation $>4 \mathrm{~cm}$ after $12 \pm 3 \mathrm{~h}$ of oxytocin administration (with a goal of 200-225 MVU or 3 contractions/10 min). As Caughey et al. [4] mentioned in their article, since the purpose of IOL is to cause a nonlaboring woman to go into labor, a reasonable definition would be to achieve active labor as a measure of success. Consequently, this was the main outcome assessed in our review. Nonetheless, most authors propose vaginal delivery as the main IOL outcome, although it depends on many other factors interacting during labor which are not necessarily related to the induction process.

Another important aspect to consider is that failed IOL diagnosis at a given time point does not always involve the performance of an immediate cesarean section in all centers. This can be explained by several studies which have shown that, continuing the induction process beyond a failed IOL diagnoses at a given time point will lead to vaginal delivery in a considerable number of cases. Women who progressed into active labor within $12 \mathrm{~h}$ had a $67-86 \%$ probability of achieving vaginal birth, whereas only $31-33 \%$ of women who reached active labor after $18 \mathrm{~h}$ had a vaginal delivery [5]. Consequently, failed IOL diagnosis does not always involve performing a cesarean section for failed IOL and, therefore, the reported rates of these two events vary between studies. In addition, the majority of guidelines do not specify a time limitation from the initiation of IOL to delivery [3], and neither has consensus about the duration of the latent and active phase been reached. The latent phase is defined as the period of time, not necessarily continuous, when there are painful contractions and some cervical change including cervical effacement and dilatation up to $4 \mathrm{~cm}$, and the onset of active labor when there are regular painful contractions and there is progressive cervical dilatation from $4 \mathrm{~cm} \mathrm{[6].}$

Despite the lack of specific recommendations, a definition of failed IOL which coincides in time with a low probability to achieve the active phase of labor seems to be the best option. Adverse outcomes related to the length of latent phase have not been extensively evaluated, although some studies have related a prolonged latent phase with subsequent labor abnormalities and the need for caesarean section [7]. A prolonged latent phase of over $12 \mathrm{~h}$ was also associated with a significantly longer duration of active labor [8]. Nevertheless, higher rates of chorioamnionitis (from $20-22$ to $25-27 \%$ ) and postpartum hemorrhage (from 11 to 16\%) have been reported after 6 and $12 \mathrm{~h}$ of latent phase, respectively $[5,9]$. In addition, economic costs related to the duration of IOL must also be taken into account [10]. This is important information which, combined with other prognostic factors, could help in the decision as to whether continuing the induction process is worthwhile or not.

In summary, it is essential to diagnose failed IOL at an appropriate time in order to counsel the patients and to decide whether to continue with the IOL or to perform a cesarean section based on the low probability of entering the active phase of labor without increasing the adverse outcomes [11]. The main objectives of this review were to identify the predictive factors of IOL failure or success as well as to highlight the current heterogeneity regarding the definition and diagnosis of failed IOL that could impair the identification of prognostic factors.

\section{Material and Methods}

\section{Identification of the Literature}

An electronic database search (PubMed, MEDLINE and Embase) up to January 2014 was performed. The search strategy for identification of studies on outcome of IOL and its predictive factors consisted of the following MeSH term combination: 'induced, labor', 'treatment outcome', 'ultrasonography' and 'cervix uteri'. 
Table 1. Characteristics of the studies included in the review

\begin{tabular}{|c|c|c|c|c|c|c|c|}
\hline First author & Year & Study & $\mathrm{n}$ & $\begin{array}{l}\text { Primary } \\
\text { outcome }\end{array}$ & $\begin{array}{l}\text { Secondary } \\
\text { outcome }\end{array}$ & Induction method & Definition of failed IOL \\
\hline Xenakis [36] & 1993 & $\begin{array}{l}\text { Prospective } \\
\text { observational }\end{array}$ & 597 & $\begin{array}{l}\text { Failed labor } \\
\text { induction }\end{array}$ & & $\begin{array}{l}\text { Bishop <7: } \mathrm{PGE}_{2} 3 \mathrm{mg} / 6 \mathrm{~h} \\
\text { Bishop >7: oxytocin }\end{array}$ & $\begin{array}{l}\text { Inability to achieve active phase of } \\
\text { labor (cervical dilation } \leq 4 \mathrm{~cm} \text { despite } \\
\text { adequate exposure to cervical priming } \\
\text { and oxytocin stimulation) after } 15 \mathrm{~h} \\
\text { primiparas/12 h multiparas }\end{array}$ \\
\hline Chandra [12] & 2001 & $\begin{array}{l}\text { Prospective } \\
\text { observational }\end{array}$ & 120 & $\begin{array}{l}\text { Vaginal } \\
\text { delivery }\end{array}$ & $\begin{array}{l}\text { Active } \\
\text { labor } 12 \mathrm{~h}\end{array}$ & $\begin{array}{l}\mathrm{PGE}_{2}, \mathrm{PGE}_{1} \text {, oxytocin } \\
+ \text { amniotomy }\end{array}$ & No vaginal delivery \\
\hline Roman [37] & 2004 & $\begin{array}{l}\text { Prospective } \\
\text { observational }\end{array}$ & 106 & $\begin{array}{l}\text { Reaching } \\
\text { active phase } \\
\text { of labor }\end{array}$ & & $\begin{array}{l}\mathrm{PGE}_{2} \text {, oxytocin } \\
+ \text { amniotomy }\end{array}$ & $\begin{array}{l}\text { Inability to achieve active phase of } \\
\text { labor (cervical dilatation } \leq 5 \mathrm{~cm} \\
\text { despite adequate uterine contraction } \\
\text { activity) }\end{array}$ \\
\hline Yang [23] & 2004 & $\begin{array}{l}\text { Prospective } \\
\text { observational }\end{array}$ & 105 & $\begin{array}{l}\text { Reaching } \\
\text { active phase } \\
\text { of labor }\end{array}$ & & $\begin{array}{l}\text { Bishop <4: } \mathrm{PGE}_{2} \\
\text { Bishop }>4 \text { : oxytocin }\end{array}$ & $\begin{array}{l}\text { Inability to achieve active phase of } \\
\text { labor (cervical dilation }<4 \mathrm{~cm} \text { despite } \\
\text { regular contractions) after } 48 \mathrm{~h}\end{array}$ \\
\hline Park [24] & 2007 & $\begin{array}{l}\text { Prospective } \\
\text { observational }\end{array}$ & 161 & $\begin{array}{l}\text { Failed labor } \\
\text { induction }\end{array}$ & & $\begin{array}{l}\text { Bishop <4: } \mathrm{PGE}_{2} \times 9 \mathrm{~h} \\
\text { + oxytocin } 12 \mathrm{~h}\end{array}$ & $\begin{array}{l}\text { Inability to achieve active phase of } \\
\text { labor (cervical dilatation of } \geq 4 \mathrm{~cm} \\
\text { within } 12 \text { h of initiating oxytocin) } \\
\text { within } 24 \text { h of induction }\end{array}$ \\
\hline Park [25] & 2009 & $\begin{array}{l}\text { Prospective } \\
\text { observational }\end{array}$ & 110 & $\begin{array}{l}\text { Failed labor } \\
\text { induction }\end{array}$ & & $\begin{array}{l}\text { Bishop }<4: \mathrm{PGE}_{2} \times 9 \mathrm{~h} \\
+ \text { oxytocin } 12 \mathrm{~h} \\
\text { Bishop }>4: \text { oxytocin }\end{array}$ & $\begin{array}{l}\text { Inability to achieve active phase of } \\
\text { labor (cervical dilatation of } \geq 4 \mathrm{~cm} \\
\text { within } 12 \text { h of initiating oxytocin) } \\
\text { within } 24 \text { h of induction }\end{array}$ \\
\hline Frederiks [13] & 2012 & $\begin{array}{l}\text { Prospective } \\
\text { observational }\end{array}$ & 400 & $\begin{array}{l}\text { Vaginal } \\
\text { delivery }\end{array}$ & $\begin{array}{l}\text { Not entering } \\
\text { the active } \\
\text { phase of labor } \\
(<4 \mathrm{~cm} \text { dilation })\end{array}$ & & No vaginal delivery \\
\hline
\end{tabular}

We checked the reference lists of relevant studies to identify cited articles not captured by the electronic searches, and the 'related articles' function in PubMed was used to complete the search. Two investigators (N.B., F.M.) independently screened titles and abstracts of electronic search results for relevance. Full texts of potentially eligible citations were obtained for further assessment. Screening for inclusion and data extraction were carried out by one reviewer (N.B.) and was checked by a second reviewer (F.M.).

We included retrospective and prospective studies, as well as systematic reviews and meta-analyses. Restrictions regarding the indication of IOL or the method of induction were not applied. The studies were included only if their main or secondary outcome was failed IOL defined as not entering the active phase of labor after $24 \mathrm{~h}$ of prostaglandin administration $\pm 12 \mathrm{~h}$ of oxytocin infusion. The data collected were: study design, exact definition of failed IOL, induction method, IOL indication, failed IOL rate, cesarean section because of failed IOL and predictors of failed IOL.

\section{Results}

\section{Description of the Studies}

The database search detected 507 publications. After the first review of the titles and abstracts, 427 were ex- cluded. The full texts of 80 articles were obtained. The main reason for exclusion was that the primary or secondary outcomes were not the established definition of failed IOL (not achieving active phase of labor) as shown in figure 1. Finally, 7 studies were eligible. In 5 of the 7 studies included, achieving the active phase of labor was the main outcome assessed. In two studies, not entering the active phase of labor was the secondary outcome [12, 13], and these were also included in the review. The characteristics of the studies included are summarized in table 1 .

\section{Indication for IOL}

Medical and elective IOL should be differentiated since IOL outcomes vary in relation to induction indication. When there is a medical indication, the potential benefit for the mother or the fetus easily supersedes the IOL risks. Recommendations for IOL for postterm gestation, preterm rupture of membranes at term and premature rupture of membranes near term with pulmonary maturity are supported by the evidence. In these IOL sit- 
Table 2. Indications for IOL

\begin{tabular}{|c|c|c|c|c|c|c|c|c|c|}
\hline First author & $\mathrm{n}$ & Postterm & $\begin{array}{l}\text { Hypertensive } \\
\text { diseases }\end{array}$ & Diabetes & IUGR & $\begin{array}{l}\text { Fetal } \\
\text { macrosomia }\end{array}$ & $\begin{array}{l}\text { Oligo- } \\
\text { hydramnios }\end{array}$ & Elective & Others \\
\hline Xenakis [36] & 597 & $22 \%$ & $32 \%$ & $16 \%$ & $18 \%$ & & & & $12 \%$ \\
\hline Yang [23] & 105 & $41(39.05)$ & $5(4.76)$ & $2(1.90)$ & $3(2.86)$ & $27(25.71)$ & $8(7.62)$ & $1(0.95)$ & $1(0.95)$ \\
\hline Park [24] & 161 & $41(25.47)$ & $2(1.24)$ & $7(4.35)$ & $19(11.80)$ & $9(5.59)$ & $71(44.1)$ & $6(3.73)$ & $10(6.21)$ \\
\hline Park [25] & 110 & $30(27.27)$ & $6(5.45)$ & $5(4.55)$ & $6(5.45)$ & $11(10)$ & $34(30.91)$ & $11(10)$ & $18(16.36)$ \\
\hline Frederiks [13] & 400 & 165 & 111 & & 45 & & & & 79 \\
\hline
\end{tabular}

Figures in parentheses indicate percentages. Premature rupture of membranes was not reported in any of the studies. IUGR = Intrauterine growth restriction.

Fig. 1. Selection of the studies included in

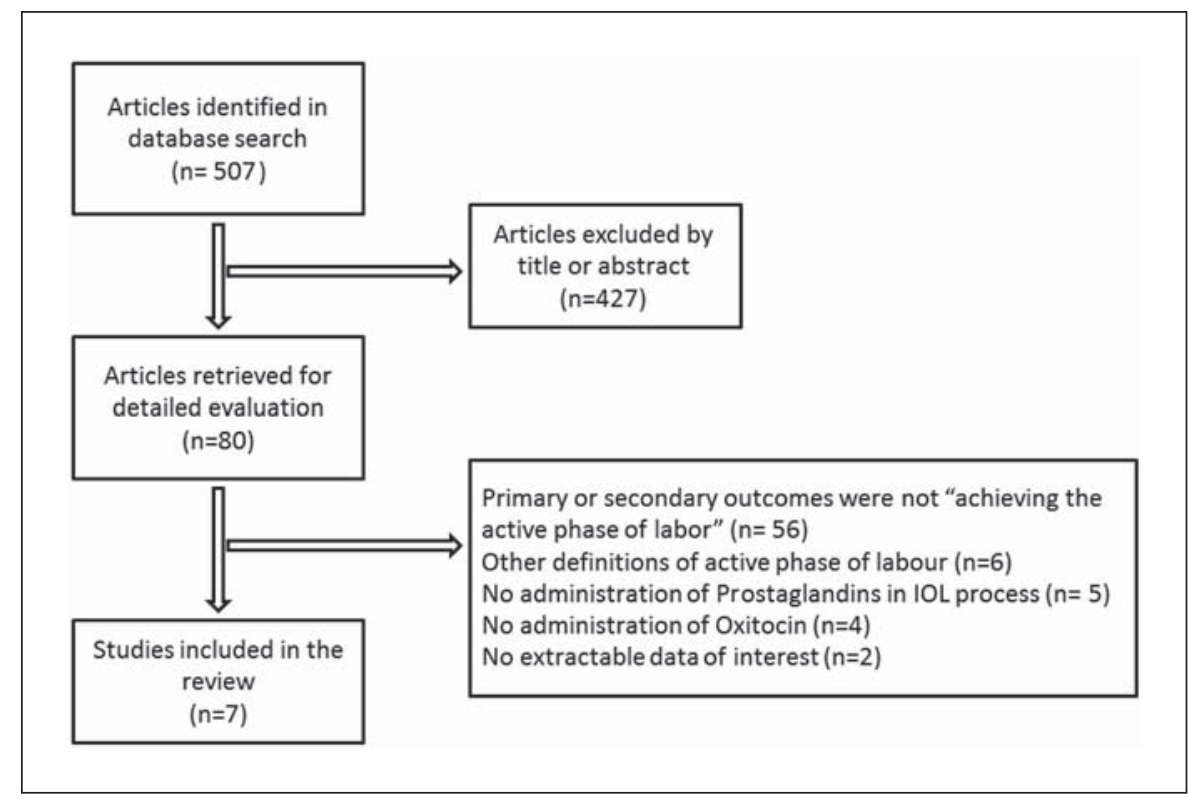
the review.

uations, an increased rate of caesarean section is not observed [14]. Intrauterine growth-restricted fetuses show higher intra-uterus mortality in the expectant group balanced by an increase in neonatal deaths in the immediate induction group. There is little evidence regarding insulin-requiring diabetes, twin gestation, fetal macrosomia, oligohydramnios, cholestasis of pregnancy, maternal cardiac disease and fetal gastroschisis $[1,14]$. Postterm pregnancy is by far the most frequent IOL indication. On the other hand, elective IOL is becoming a more frequent IOL indication especially based on the latest scientific evidence [15]. Despite the low risk of maternal and fetal complications related to elective IOL, favorable cervical and obstetrical conditions should be a prerequisite when indicating elective IOL in order to further decrease the potential adverse outcomes associated with this interven- tion. IOL indications are shown in table 2. In the studies included in our review, the elective induction rate varies from 0.95 to $10 \%$, showing a progressive increase in almost all settings. In one study [12] IOL indications were not reported.

\section{Rates of Cesarean Section for Failed IOL}

A higher rate of maternal and fetal morbidity especially with an increased risk of cesarean section has been associated with IOL $[16,17]$, but this association has been challenged in recent years. A Cochrane review concluded that cesarean section rates and assisted vaginal delivery rates are not increased by IOL at term when a medical indication exists $[18,19]$. It has been demonstrated that the cesarean rate does not increase, or it even decreases with a policy of IOL at or beyond 41 weeks of gestation, 
in addition to improving perinatal outcomes $[15,20]$. Conflicting results are reported below 40-41 weeks of gestation [21, 22].

All the data cited suggest that in the next years the number of IOL may increase further. Consequently, it is of paramount importance to reach consensus on the management of this extremely frequent intervention.

As mentioned above, the diagnosis of failed IOL does not always imply performing a cesarean section at this time. In addition, not all the studies included in the review reported both failed IOL diagnosis and cesarean section for failed IOL rates as shown in table 3. Nevertheless, despite the limited number of studies, a nonnegligible proportion of patients underwent a vaginal delivery after being diagnosed with failed IOL in 3 of the 7 studies included [23-25].

\section{Factors Determining IOL Outcome}

Despite the large number of studies conducted, no good predictive factors were found to successfully identify the group of patients who will not respond to physical or pharmacological induction, and hence achieve the active phase of labor. Heterogeneity between the outcomes assessed contributes to the lack of conclusive results.

Cervical status, mainly measured by the Bishop score and parity, has been shown to be the main predictor of successful labor induction $[26,27]$. Other predictors such as maternal age, weight, height, body mass index, ethnicity and socioeconomic status have been reported. Obstetric and medical history such as gestational age at delivery, birth weight and amniotic fluid index have also been described [28]. The relevant predictive factors reported in the studies included in the review are shown in table 4.

\section{Gestational Age}

Placental function declines while fetal intolerance to labor and fetal weight increases with gestational age. All these factors could contribute to increasing the rate of cesarean section. However, not entering the active phase of labor, and therefore failed induction, are not related to the three factors described above [29]. Earlier gestational age was found to be a significant predictive factor for failed IOL in one of the studies included [24].

\section{Maternal Characteristics}

Maternal age contributes to a higher prevalence of maternal complications during pregnancy and therefore to an increased rate of IOL, including those with unfavor-
Table 3. Diagnosis of failed IOL and cesarean section for failed IOL

\begin{tabular}{lll}
\hline First author & Failed IOL & Cesarean section \\
& & \\
\hline Xenakis [36] & Total: $3.69 \%$ & Not specified \\
& Bishop $<3: 9.4 \%$ & \\
& Bishop $>3: 0.7 \%$ & \\
Chandra [12] & Not specified & Not specified \\
Roman [37] & $16(15.1 \%)$ & $16(15.1 \%)$ \\
Yang [23] & $12(11.4 \%)$ & $8(7.6 \%)$ \\
Park [24] & $55(33 \%)$ & $5(31 \%)$ \\
Park [25] & $15(14 \%)$ & $2(1.8 \%)$ \\
Frederiks [13] & $11.3 \%$ & Not specified \\
\hline
\end{tabular}

Table 4. Predictive factors of IOL outcome

\begin{tabular}{|c|c|}
\hline First author & Multiple logistic regression analysis \\
\hline Xenakis [36] & $\begin{array}{l}\text { Total: Bishop <3: OR 13.6; 95\% CI 3.7-36.6 } \\
\text { Primiparas: Bishop <3: OR 22.9; 95\% CI 3.1-98 } \\
\text { Multiparas: Bishop <3: OR 6.6, 95\%; CI 1.1-28.1 }\end{array}$ \\
\hline Chandra [12] & $\begin{array}{l}\text { Maternal weight: OR } 0.96 ; 95 \% \text { CI } 0.94-0.8 \\
\text { Cervical dilatation: OR } 6.08 ; 95 \% \text { CI } 1.70-21.68 \\
\text { Cervical effacement: OR } 2.34 ; 95 \% \text { CI } 1.16-4.73\end{array}$ \\
\hline Roman [37] & $\begin{array}{l}\text { Bishop: OR } 2.25 \text {; } 95 \% \text { CI } 1.30-3.91 \\
\text { Bishop cutoff } 4: \text { S } 87.5 \% / \text { E } 45.5 \% \\
\text { Clinical CL: OR } 3.95 ; 95 \% \text { CI } 1.3-11.7 \\
\text { CL cutoff } 30 \mathrm{~mm} \text { : S 56.3\%/E 65.6\%/PPV 22.5\%/ } \\
\text { NPV } 89.4 \%\end{array}$ \\
\hline Yang [23] & $\begin{array}{l}\text { Bishop >4: S 51\%/E 75\%/PPV 94\%/NPV 16\% } \\
\text { CL: OR 0.24; 95\% CI 0.096-0.59 } \\
\text { CL cutoff } 30 \text { mm: S 83\%/E 75\% }\end{array}$ \\
\hline Park [24] & $\begin{array}{l}\text { GA: OR } 0.53 ; 95 \% \text { CI } 0.39-0.73 \\
\text { CL: OR } 2.80 ; 95 \% \text { CI } 1.46-5.38 \\
\text { CL cutoff } 28 \text { mm: S } 62 \% / E 60 \%\end{array}$ \\
\hline Park [25] & Bishop: $\mathrm{OR}=0.621 ; 95 \%$ CI $0.391-0.988$ \\
\hline Frederiks [13] & No multivariate analysis \\
\hline
\end{tabular}

able conditions. Dysfunctional myometrium could also lead to longer labors and, consequently, more failed IOL [30]. However, no significant relationship was found between maternal age and IOL outcome in the studies reviewed. A higher body mass index is associated with a higher fetal weight and pregnancy-related complications, both conditions being linked to an increased risk of cesar- 
ean section. However, regarding the achievement of the active phase of labor itself, this relation has not been demonstrated [31-33].

\section{Cervical Status}

As prelabor cervical status has been recognized as the most important predictor of induction success, many studies have evaluated the relationship between the Bishop score and sonographic cervical characteristics with IOL outcome. Regarding the predictive value of the Bishop score, a meta-analysis [34] and a recently published systematic review [35] reached divergent results. Teixeira et al. [34] concluded that the Bishop score still seems to be the most accurate predictive factor of vaginal delivery after IOL. When referring to achieving the active phase of labor, either with no time limit for this to occur or within a certain time interval, the same conclusion cannot be assumed due to lack of studies assessing this outcome. On the other hand, Kolkman et al. [35] showed that a Bishop score of 4,5 or 6 was a poor predictor of IOL success if that was defined as achieving a vaginal delivery. For the prediction of cesarean delivery, the sensitivity and specificity of a Bishop score $<6$ was 78 and $44 \%$, respectively, and of a Bishop score $<9$ was 95 and $30 \%$. This study recommended not using the Bishop score in decision making. Three of the studies included in our review $[25,36$, 37] found the Bishop score to be a significant predictive factor of IOL outcome, although it was not a strong predictor in any of the studies. Cervical dilatation and cervical effacement were independently associated with 'achieving active phase of labor' in one study [12]. The Bishop score was not an independent predictive factor in the other studies included (table 4).

Regarding sonographic cervical assessment to predict IOL outcome, conflicting results are also reported. A recent meta-analysis found limited value of cervical length and cervical wedging in predicting the outcome of labor in clinical practice [38]. Moreover, of the 31 studies included in the meta-analysis only 2 reported the outcome 'not achieving the active phase of labor'. The sensitivity and specificity of cervical length in the studies included in that review were 56-66\% [37] and 83-75\% [23], respectively, for a cutoff of $30 \mathrm{~mm}$. In another systematic review, Hatfield et al. [26] also concluded that sonographic cervical length was not an effective or, at most, a weak predictor for any of the outcomes assessed (mode of delivery, vaginal delivery within $24 \mathrm{~h}$ and achievement of the active phase of labor). Moreover, when comparing the Bishop score with cervical length measured by ultrasound, sonographic cervical length was not superior to the Bishop score. Cervical length was found to be an independent predictive factor in 2 of the studies included in our review $[23,24]$. Other sonographic characteristics studied such as cervical wedging (sensitivity $37 \%$, specificity $80 \%$ ) [38] and fetal head position (sensitivity $39 \%$, specificity $71 \%$ ) have not been shown to be good predictors [39].

To summarize, there is an association between the Bishop score and cervical length measured by ultrasound and IOL outcome, but this relation does not always result in a good predictor. Therefore, future studies should explore other cervical characteristics, a combination of factors or focus on new diagnostic tools.

Some predictive models have been developed to predict cesarean section risk after IOL [40-42], although none of these models evaluated the prediction of achieving the active phase of labor. Moreover, their use in clinical practice is not recommended due to their moderate predictive capacity [43].

\section{Other Prognostic Factors}

Biochemical Markers

Biochemical markers, such as fetal fibronectin and IGFBP-1, have also been studied, but neither have shown to be superior to the Bishop score regarding the prediction of successful IOL [44-46].

\section{New Predictive Factors Based on Image Analysis}

A wide range of technologies and devices assessing cervical characteristics are under development, but only two have been evaluated in women undergoing IOL: light-induced fluorescence (LIF) and elastography.

A method to measure cervical collagen using LIF has been developed [47, 48]. Fittkow et al. [49] found that LIF measurements correlate negatively with gestational age and positively with the time to delivery, although the correlation was weak. They applied this technique to assess cervical ripening in an IOL setting. LIF and the Bishop score were measured at the beginning of IOL. No correlation was found between the two parameters. The same measurements were performed $4 \mathrm{~h}$ after prostaglandin administration, finding a statistically significant inverse correlation. On the other hand, elastography is based on determining motion in areas of the cervix relative to others, defining an elastography index (EI). In a study of 29 women undergoing IOL, those with successful IOL had a higher EI of the internal os than those with failed IOL. The EI was not predictive in other cervical regions. Muscatello et al. [50] also reported higher rates of cesarean section in those women with a higher EI. However, a re- 
cent study showed that elastographic score at the internal os was unlikely to be useful in the prediction of vaginal delivery and induction-to-delivery interval [51]. A technical limitation is that this measurement still depends on the force exerted by the operator and, therefore, further investigation is needed [52].

A variety of other techniques and devices are being investigated to determine cervical composition and behavior, although up to now they are only focused on preterm birth prediction [53]. Some examples of these methods are acoustic attenuation [54] and electric impedance [55] which assess cervical hydration. Second harmonic generation [56], Raman spectroscopy $[57,58]$ and backscattered power loss [58] also study cervical collagen microstructure. Regarding the assessment of tissue elasticity, several strategies such as the cervical consistency index [59] and a cervical aspiration device [60] have also been evaluated. The absence of the cervical gland area has also been proposed as a predictor of preterm birth $[61,62]$.

To summarize, there are a large number of studies describing new parameters to better assess cervical changes during pregnancy, thereby reflecting the strong interest of the scientific community in finding an objective and applicable evaluation method to predict relevant clinical outcomes such as IOL failure or success and preterm birth risk. Unfortunately, despite being very common situations, a robust predictor has not as yet been found.

\section{Discussion}

IOL is an extremely common procedure performed in all obstetrical settings. In about $20 \%$ of pregnancies, labor is induced for a variety of reasons, postterm pregnancy being the most frequent indication. Despite its enormous medical and economic impact, there are still many controversies regarding IOL definition, indications, management and outcomes. Heterogeneity between IOL protocols and definitions makes it very difficult to draw conclusions based on published studies.

The first aspect to highlight is the lack of a generally accepted definition of failed IOL. Most studies define failed IOL as the impossibility to achieve a vaginal delivery, although there are many other factors appearing during labor that may hinder or prevent a vaginal delivery, which may explain why a robust predictor has not been found. From our point of view, the definition of failed IOL should be consistent with the IOL definition itself, which is the achievement of the active phase of labor. Therefore, failed IOL should be defined as the inability to achieve this. An important finding of this review is that only 7 of all the studies reviewed assessed achieving the active phase of labor as a primary or secondary IOL outcome. This implies that most of the existing literature is based on a very general outcome, evaluating a final result such as the vaginal delivery, and therefore, adding confounding factors.

The second important conclusion of this review is that clinical risk factors themselves have a too low predictive value to be translated into a useful clinical tool. In contrast, cervical status remains the most important predictor of IOL outcome, although the value of the parameters explored to date is limited. Consequently, great efforts are being made in order to find an objective method to better assess cervical status. To find or develop predictive tools to identify those women exposed to IOL who may not reach the active phase of labor is crucial to minimize the risks and costs associated with IOL failure.

To conclude, a generally accepted and adequate definition of failed IOL is an essential requisite to analyze and obtain solid results and conclusions. On the other hand, improving the prediction of IOL failure is currently a major challenge in obstetrics due to the negative impact of a failed IOL in several fields. Our inability to predict this leads to long and expensive labor inductions. The identification of such women would allow individualized counseling and potentially improve outcomes in terms of health (adverse perinatal and maternal outcomes due to prolonged labor inductions), economic burden (costs in terms of staff, medication and hospitalization) and health system quality perception (maternal discomfort). Therefore, new predictors for this frequent intervention are urgently needed in order to improve IOL management and outcome.

\begin{tabular}{|c|c|}
\hline References & $\begin{array}{l}\text { Talaulikar VS, Arulkumaran S: Failed induc- } \\
\text { tion of labor: Strategies to improve the success } \\
\text { rates. Obstet Gynecol Surv 2011;66:717-728. } \\
2 \text { Lin MG, Rouse DJ: What is a failed labor in- } \\
\text { duction? Clin Obstet Gynecol 2006;49:585- } \\
593 \text {. } \\
3 \text { ACOG Practice Bulletin No. 107: Induction } \\
\text { of labor. Obstet Gynecol 2009;114:386-397. } \\
4 \text { Caughey AB, Sundaram V, Kaimal AJ, } \\
\text { Gienger A, Cheng YW, McDonald KM, Shaf- } \\
\text { fer BL, Owens DK, Bravata DM: Systematic } \\
\text { review: elective induction of labor versus ex- } \\
\text { pectant management of pregnancy. Ann In- } \\
\text { tern Med 2009;151:252-263, W53-63. } \\
5 \text { Simon CE, Grobman WA: When has an in- } \\
\text { duction failed? Obstet Gynecol 2005; 105: } \\
\text { 705-709. }\end{array}$ \\
\hline
\end{tabular}

Failed Induction of Labor and Its Predictive Factors
DOI: $10.1159 / 000433429$ 
6 The Royal College of Midwives: Evidence Based Guidelines for Midwifery-Led Care in Labour. Latent Phase. London, The Royal College of Midwives, 2012.

7 Chelmow D, Kilpatrick SJ, Laros RK Jr: Maternal and neonatal outcomes after prolonged latent phase. Obstet Gynecol 1993;81:486491.

8 Dencker A, Berg M, Bergqvist L, Lilja H: Identification of latent phase factors associated with active labor duration in low-risk nulliparous women with spontaneous contractions. Acta Obstet Gynecol Scand 2010;89:1034-1039.

9 Rouse DJ, Owen J, Hauth JC: Criteria for failed labor induction: prospective evaluation of a standardized protocol. Obstet Gynecol 2000;96:671-677.

10 Rouse DJ, Weiner SJ, Bloom SL, Varner MW, Spong CY, Ramin SM, Caritis SN, Grobman WA, Sorokin Y, Sciscione A, Carpenter MW, Mercer BM, Thorp JM Jr, Malone FD, Harper M, Iams JD, Anderson GD: Failed labor induction: toward an objective diagnosis. Obstet Gynecol 2011;117:267-272.

-11 Cromi A, Ghezzi F, Tomera S, Scandroglio S, Colombo G, Bolis P: Cervical ripening with a Foley catheter: the role of pre- and postripening ultrasound examination of the cervix. Am J Obstet Gynecol 2007;196:41.e1-7.

12 Chandra S, Crane JM, Hutchens D, Young DC: Transvaginal ultrasound and digital examination in predicting successful labor induction. Obstet Gynecol 2001;98:2-6.

13 Frederiks F, Lee S, Dekker G: Risk factors for failed induction in nulliparous women. J Matern Fetal Neonatal Med 2012;25:2479-2487.

-14 Mozurkewich E, Chilimigras J, Koepke E, Keeton K, King VJ: Indications for induction of labour: a best-evidence review. BJOG 2009; 116:626-636.

15 Darney BG, Snowden JM, Cheng YW, Jacob L, Nicholson JM, Kaimal A, Dublin S, Getahun D, Caughey AB: Elective induction of labor at term compared with expectant management: maternal and neonatal outcomes. Obstet Gynecol 2013;122:761-769.

16 Battista L, Chung JH, Lagrew DC, Wing DA: Complications of labor induction among multiparous women in a community-based hospital system. Am J Obstet Gynecol 2007; 197:241.e1-7, discussion 322-323.e1-4.

17 Grivell RM, Reilly AJ, Oakey H, Chan A, Dodd JM: Maternal and neonatal outcomes following induction of labor: a cohort study. Acta Obstet Gynecol Scand 2011;91:198-203.

18 Gulmezoglu AM, Crowther CA, Middleton P: Induction of labour for improving birth outcomes for women at or beyond term. Cochrane Database Syst Rev 2006;CD004945.

19 Dare MR, Middleton P, Crowther CA, Flenady VJ, Varatharaju B: Planned early birth versus expectant management (waiting) for prelabour rupture of membranes at term (37 weeks or more). Cochrane Database Syst Rev 2006;CD005302.
20 Stock SJ, Ferguson E, Duffy A, Ford I, Chalmers J, Norman JE: Outcomes of elective induction of labour compared with expectant management: population based study. BMJ 2012;344:e2838.

21 Sanchez-Ramos L, Olivier F, Delke I, Kaunitz AM: Labor induction versus expectant management for postterm pregnancies: a systematic review with meta-analysis. Obstet Gynecol 2003;101:1312-1318.

22 Nicholson JM, Caughey AB, Stenson MH, Cronholm P, Kellar L, Bennett I, Margo K, Stratton J: The active management of risk in multiparous pregnancy at term: association between a higher preventive labor induction rate and improved birth outcomes. Am J Obstet Gynecol 2009;200:250.e1-250.e13.

23 Yang SH, Roh CR, Kim JH: Transvaginal ultrasonography for cervical assessment before induction of labor. J Ultrasound Med 2004; 23:375-382, quiz 384-385.

24 Park KH: Transvaginal ultrasonographic cervical measurement in predicting failed labor induction and cesarean delivery for failure to progress in nulliparous women. J Korean Med Sci 2007;22:722-727.

25 Park KH, Hong JS, Shin DM, Kang WS: Prediction of failed labor induction in parous women at term: role of previous obstetric history, digital examination and sonographic measurement of cervical length. J Obstet Gynaecol Res 2009;35:301-306.

26 Hatfield AS, Sanchez-Ramos L, Kaunitz AM: Sonographic cervical assessment to predict the success of labor induction: a systematic review with metaanalysis. Am J Obstet Gynecol 2007;197:186-192.

27 Grobman WA: Predictors of induction success. Semin Perinatol $2012 ; 36: 344-347$.

28 Crane JM: Factors predicting labor induction success: a critical analysis. Clin Obstet Gynecol 2006;49:573-584.

29 Caughey AB, Stotland NE, Washington AE, Escobar GJ: Maternal and obstetric complications of pregnancy are associated with increasing gestational age at term. Am J Obstet Gynecol 2007;196:155.e1-6.

30 Greenberg MB, Cheng YW, Sullivan M, Norton ME, Hopkins LM, Caughey AB: Does length of labor vary by maternal age? Am J Obstet Gynecol 2007;197:428.e1-7.

31 Nuthalapaty FS, Rouse DJ, Owen J: The association of maternal weight with cesarean risk, labor duration, and cervical dilation rate during labor induction. Obstet Gynecol 2004; 103:452-456.

- 32 Ecker JL, Chen KT, Cohen AP, Riley LE, Lieberman ES: Increased risk of cesarean delivery with advancing maternal age: indications and associated factors in nulliparous women. Am J Obstet Gynecol 2001;185: 883-887.
33 Weiss JL, Malone FD, Emig D, Ball RH, Nyberg DA, Comstock CH, Saade G, Eddleman K, Carter SM, Craigo SD, Carr SR, D'Alton ME: Obesity, obstetric complications and cesarean delivery rate - a population-based screening study. Am J Obstet Gynecol 2004; 190:1091-1097.

-34 Teixeira C, Lunet N, Rodrigues T, Barros H: The Bishop score as a determinant of labour induction success: a systematic review and meta-analysis. Arch Gynecol Obstet 2012; 286:739-753.

35 Kolkman DG, Verhoeven CJ, Brinkhorst SJ, van der Post JA, Pajkrt E, Opmeer BC, Mol BW: The Bishop score as a predictor of labor induction success: a systematic review. Am J Perinatol 2013;30:625-630.

36 Xenakis EM, Piper JM, Conway DL, Langer O: Induction of labor in the Nineties: conquering the unfavorable cervix. Obstet Gynecol 1997;90:235-239.

37 Roman H, Verspyck E, Vercoustre L, Degre S, Col JY, Firmin JM, Caron P, Marpeau L: Does ultrasound examination when the cervix is unfavorable improve the prediction of failed labor induction? Ultrasound Obstet Gynecol 2004;23:357-362.

38 Verhoeven CJ, Opmeer BC, Oei SG, Latour V, van der Post JA, Mol BW: Transvaginal sonographic assessment of cervical length and wedging for predicting outcome of labor induction at term: a systematic review and meta-analysis. Ultrasound Obstet Gynecol 2013; 42:500-508.

- 39 Verhoeven CJ, Mulders LG, Oei SG, Mol BW: Does ultrasonographic foetal head position prior to induction of labour predict the outcome of delivery? Eur J Obstet Gynecol Reprod Biol 2012;164:133-137.

40 Peregrine E, O’Brien P, Omar R, Jauniaux E: Clinical and ultrasound parameters to predict the risk of cesarean delivery after induction of labor. Obstet Gynecol 2006;107:227-233.

41 Rane SM, Guirgis RR, Higgins B, Nicolaides $\mathrm{KH}$ : Models for the prediction of successful induction of labor based on pre-induction sonographic measurement of cervical length. J Matern Fetal Neonatal Med 2005;17:315-322.

42 Keepanasseril A, Suri V, Bagga R, Aggarwal $\mathrm{N}$ : A new objective scoring system for the prediction of successful induction of labour. J Obstet Gynaecol 2012;32:145-147.

43 Verhoeven CJ, Oudenaarden A, Hermus MA, Porath MM, Oei SG, Mol BW: Validation of models that predict cesarean section after induction of labor. Ultrasound Obstet Gynecol 2009;34:316-321.

44 Reis FM, Gervasi MT, Florio P, Bracalente G, Fadalti M, Severi FM, Petraglia F: Prediction of successful induction of labor at term: role of clinical history, digital examination, ultrasound assessment of the cervix, and fetal fibronectin assay. Am J Obstet Gynecol 2003; 189:1361-1367. 
-45 Ojutiku D, Jones G, Bewley S: Quantitative foetal fibronectin as a predictor of successful induction of labour in post-date pregnancies. Eur J Obstet Gynecol Reprod Biol 2002;101: 143-146.

46 Nuutila M, Hiilesmaa V, Karkkainen T, Ylikorkala O, Rutanen EM: Phosphorylated isoforms of insulin-like growth factor binding protein-1 in the cervix as a predictor of cervical ripeness. Obstet Gynecol 1999;94:243249.

-47 Maul H, Saade G, Garfield RE: Prediction of term and preterm parturition and treatment monitoring by measurement of cervical cross-linked collagen using light-induced fluorescence. Acta Obstet Gynecol Scand 2005; 84:534-536.

48 Schlembach D, Mackay L, Shi L, Maner WL, Garfield RE, Maul H: Cervical ripening and insufficiency: from biochemical and molecular studies to in vivo clinical examination. Eur J Obstet Gynecol Reprod Biol 2009;144(suppl 1):S70-S76.

- 49 Fittkow CT, Maul H, Olson G, Martin E, MacKay LB, Saade GR, Garfield RE: Lightinduced fluorescence of the human cervix decreases after prostaglandin application for induction of labor at term. Eur J Obstet Gynecol Reprod Biol 2005;123:62-66.

50 Muscatello A, Di Nicola M, Accurti V, Mastrocola N, Franchi V, Colagrande I, Patacchi- ola F, Carta G: Sonoelastography as method for preliminary evaluation of uterine cervix to predict success of induction of labor. Fetal Diagn Ther 2014;35:57-61.

-51 Pereira S, Frick AP, Poon LC, Zamprakou A, Nicolaides KH: Successful induction of labor: prediction by pre-induction cervical length, angle of progression and cervical elastography. Ultrasound Obstet Gynecol 2014;44: 468-475.

52 Swiatkowska-Freund M, Preis K: Elastography of the uterine cervix: implications for success of induction of labor. Ultrasound Obstet Gynecol 2011;38:52-56.

53 Feltovich H, Hall TJ, Berghella V: Beyond cervical length: emerging technologies for assessing the pregnant cervix. Am J Obstet Gynecol 2012;207:345-354.

54 McFarlin BL, Bigelow TA, Laybed Y, O’Brien WD, Oelze ML, Abramowicz JS: Ultrasonic attenuation estimation of the pregnant cervix: a preliminary report. Ultrasound Obstet Gynecol 2010;36:218-225.

55 Jokhi RP, Brown BH, Anumba DO: The role of cervical electrical impedance spectroscopy in the prediction of the course and outcome of induced labour. BMC Pregnancy Childbirth 2009;9:40

56 Akins ML, Luby-Phelps K, Mahendroo M: Second harmonic generation imaging as a potential tool for staging pregnancy and predict- ing preterm birth. J Biomed Opt 2010;15: 026020.

57 Vargis E, Byrd T, Logan Q, Khabele D, Mahadevan-Jansen A: Sensitivity of Raman spectroscopy to normal patient variability. J Biomed Opt 2011;16:117004.

58 Feltovich H, Nam K, Hall TJ: Quantitative ultrasound assessment of cervical microstructure. Ultrason Imaging 2010;32:131-142.

59 Parra-Saavedra M, Gomez L, Barrero A, Parra G, Vergara F, Navarro E: Prediction of preterm birth using the cervical consistency index. Ultrasound Obstet Gynecol 2011;38:4451.

60 Badir S, Mazza E, Zimmermann R, Bajka M: Cervical softening occurs early in pregnancy: characterization of cervical stiffness in 100 healthy women using the aspiration technique. Prenat Diagn 2013;33:737-741.

61 Afzali N, Mohajeri M, Malek A, Alamatian A: Cervical gland area: a new sonographic marker in predicting preterm delivery. Arch Gynecol Obstet 2012;285:255-258.

62 Kahyaoglu S, Kahyaoglu I, Kaymak O, Sagnic S, Mollamahmutoglu L, Danisman N: Can transvaginal ultrasonographic evaluation of the endocervical glandular area predict preterm labor among patients who received tocolytic therapy for threatened labor: a cross-sectional study. J Matern Fetal Neonatal Med 2013;26:920-925.
Failed Induction of Labor and Its Predictive Factors
Fetal Diagn Ther 2015;38:161-169 


\section{Erratum}

In the article by Baños N, Migliorelli F, Posadas E, Ferreri J and Palacio M, entitled 'Definition of failed induction of labor and its predictive factors: two unsolved issues of an everyday clinical situation' [Fetal Diagnosis and Therapy 2015;38:161-169, DOI: 10.1159/ 000433429], the following changes in the author affiliations need to be added:

\section{Núria Baños $^{\mathrm{a}} \quad$ Federico Migliorelli $^{\mathrm{a}} \quad$ Eduardo Posadas $^{\mathrm{a}} \quad$ Janisse Ferreri $^{\mathrm{a}}$ Montse Palacio ${ }^{\mathrm{a}, \mathrm{b}}$ \\ aBCNatal - Barcelona Center for Maternal-Fetal and Neonatal Medicine, Hospital Clínic and Hospital Sant Joan de Deu, Fetal i+D Fetal Medicine Research Center, IDIBAPS, Uni- versity of Barcelona, Barcelona, and ${ }^{\mathrm{b}}$ Centre for Biomedical Research on Rare Diseases (CIBER-ER), Spain}

Furthermore, we would like to give a new email address (NBANOS@clinic.cat) and we would like to add the following acknowledgments:

\section{Acknowledgments}

This publication has been funded with support of the Erasmus + Programme of the European Union (Framework Agreement No.: 2013-0040). This publication reflects the views only of the author, and the Commission cannot be held responsible for any use which may be made of the information contained therein. Additionally, the work was supported by grants from The Cerebra Foundation for the Brain Injured Child (Carmarthen, Wales, UK), Obra Social 'la Caixa', Instituto de Salud Carlos III and Ministerio de Economia y Competitividad (PI10/01308, EC07/90023) and Ministerio de Sanidad y Política Social (EC10-065, TRA-096), cofinanciados por el Fondo Europeo de Desarrollo Regional de la Unión Europea 'Una manera de hacer Europa', Spain. 